
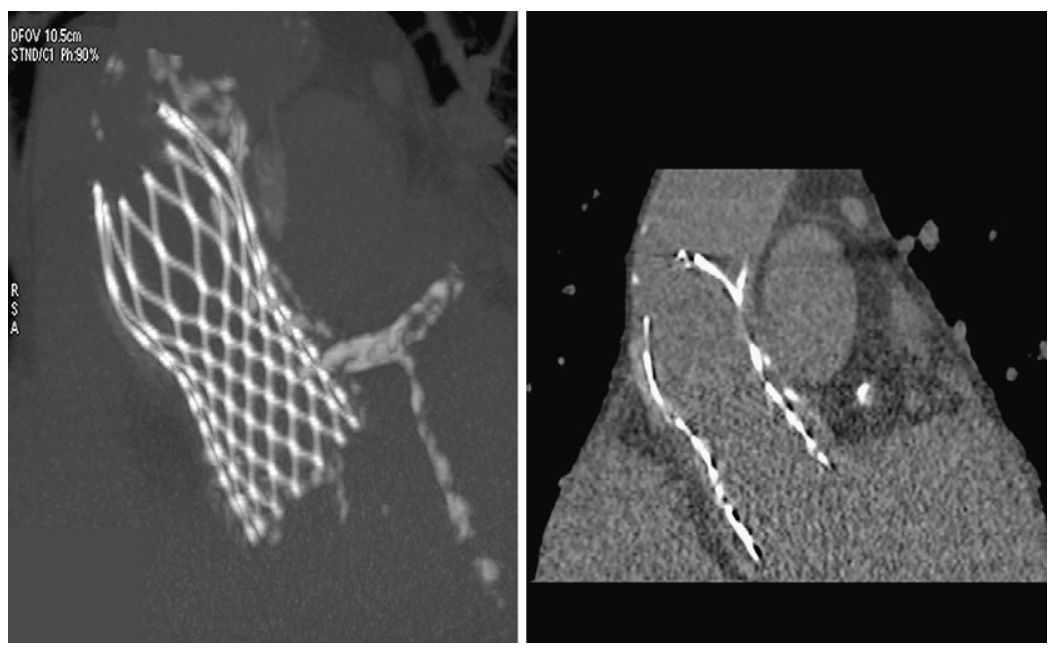

FIGURE 2. Computed tomographic scan confirmed the good positioning of the CoreValve Revalving System.

In our case, AR was actually due to the sequelae of endocarditis and not to structural valve degeneration. Technical issues for TAVI in patients with stentless bioprostheses are different from those in patients with native aortic stenosis or a stented bioprosthesis. Positioning may be more difficult because of the absence of calcification, and the role of concomitant TEE should be emphasized. The absence of calcification or stents may also theoretically increase the risk of prosthesis migration because of potentially less stable anchorage on the aortic annulus. However, this report illustrates the feasibility of TAVI in patients with severe dysfunction of a stentless bioprosthesis.

Valve-in-valve implantation may represent a promising opportunity for the future,,$^{5}$ inasmuch as limited durability is the major concern of stented or stentless bioprostheses. Further studies including a large number of patients and longer follow-up are required to define the exact role of TAVI in elderly patients with a degenerated bioprosthesis that requires reintervention.

\section{References}

1. Piazza N, Grube E, Gerckens U, den Heijer P, Linke A, Luha O, et al. Procedural and 30-day outcomes following transcatheter aortic valve implantation using the third generation ( $18 \mathrm{Fr}$ ) CoreValve Revalving System: results from the multicentre, expanded evaluation registry 1-year following CE mark approval. EuroIntervention. 2008;4:242-9.

2. Walther T, Falk V, Dewey T, Kempfert J, Emrich F, Pfannmuller B, et al. Valvein-a-valve concept for transcatheter minimally invasive repeat xenograft implantation. J Am Coll Cardiol. 2007;50:56-60.

3. Wenaweser P, Buellesfeld L, Gerckens U, Grube E. Percutaneous aortic valve replacement for severe aortic regurgitation in degenerated bioprosthesis: the first valve in valve procedure using the Corevalve Revalving system. Catheter Cardiovasc Interv. 2007;70:760-4.

4. Hvass U, Baron F, Elsebaey A, Nguyen D, Flecher E. The Stentless Cryo-Life O'Brien porcine aortic valve at 10 years. J Heart Valve Dis. 2004;13:977-83; discussion 983 .

5. Webb JG. Transcatheter valve in valve implants for failed prosthetic valves. Catheter Cardiovasc Interv. 2007;70:765-6.

\title{
Feasibility of transapical aortic valve implantation fully guided by transesophageal echocardiography
}

Eric Dumont, MD, Jerôme Lemieux, MD, Daniel Doyle, MD, and Josep Rodés-Cabau, MD, FESC, Québec, Canada

From the Quebec Heart Institute, Laval Hospital, Québec, Canada.

Received for publication Jan 23, 2009; revisions received March 15, 2009; accepted for publication March 20, 2009; available ahead of print June 1, 2009.

Address for reprints: Josep Rodés-Cabau, MD, FESC, Québec Heart Institute, Laval Hospital, 2725 Chemin Ste-Foy, G1V 4G5 Québec, Canada (E-mail: josep. rodes@crhl.ulaval.ca).

J Thorac Cardiovasc Surg 2009; 138:1022-4

$0022-5223 / \$ 36.00$

Copyright (c) 2009 by The American Association for Thoracic Surgery doi:10.1016/j.jtcvs.2009.03.036
Transapical aortic valve implantation (TAVI) is emerging as an alternative to surgical aortic valve replacement for the treatment of patients with severe aortic stenosis considered to be at very high or prohibitive surgical risk. ${ }^{1}$ In this report we present, for the first time, a case of TAVI fully guided by transesophageal echocardiography (TEE), with no angiography, and we also discuss the usefulness of echocardiography for guiding TAVI procedures. 


\section{CLINICAL SUMMARY}

A 73-year-old woman with severe aortic stenosis was admitted to our hospital with a diagnosis of pulmonary edema. She had a history of bypass grafting, stroke, peripheral vascular disease, severe calcification of the ascending aorta, and chronic renal failure. Doppler echocardiography showed a mean aortic gradient of $33 \mathrm{~mm} \mathrm{Hg}$, an aortic valve area of $0.65 \mathrm{~cm}^{2}$, and a left ventricular ejection fraction of $30 \%$. Coronary angiography showed patency of all grafts. The patient was refused for conventional surgical aortic valve replacement (Society of Thoracic Surgeons score $14.5 \%$ ) and she was then evaluated for transcatheter valve implantation. Contrast-enhanced computed tomography showed complete occlusion of both iliac arteries precluding a retrograde approach through the femoral artery, and TAVI was then proposed. The procedure was authorized by Health Canada under compassionate special access.

The procedure was performed in the operating room by a team of cardiac surgeons and interventional cardiologists using techniques extensively described in previous reports. ${ }^{2}$ On the basis of an aortic annulus measurement of $20 \mathrm{~mm}$ by TEE, a 23-mm Edwards SAPIEN valve (Edwards Lifesciences Inc, Irvine, Calif) was selected for implantation. In our routine practice, a pigtail catheter is advanced up to the aortic valve to guide valve positioning by angiography, but in this case iliac occlusion precluded the femoral approach. Furthermore, there was a radial thrombosis at the right side and left radial puncture was associated with severe vasospasm precluding any catheter advancement. Consequently, we then decided to guide the procedure by TEE exclusively. We took special care to appropriately identify the aortic and ventricular ends of the stent containing the valve at TEE (Figure 1, A). The valve was positioned with about half of the stent below and half above the aortic annulus as determined by TEE. The hinge point of the anterior mitral leaflet was also used as an anatomic marker for positioning the ventricular end of the stent (Figure 1,B). Valve deployment was performed under rapid pacing and, importantly, the final position of the valve was verified again by TEE during rapid pacing just before deployment (Figure 1, $C$ and $D$ ). TEE images after valve deployment showed the correct position of the valve, with its ventricular end located at the hinge point of the mitral valve (Figure 2, $A$ ). Doppler echocardiography showed a mean residual aortic gradient and aortic valve area of $4 \mathrm{~mm} \mathrm{Hg}$ and $1.32 \mathrm{~cm}^{2}$, respectively, and the absence of aortic regurgitation (Figure 2, $B$ ). The postoperative period was uneventful and the patient was discharged 5 days after the procedure. At 1-month follow-up, the patient was in New York Heart Association functional class II and there were no changes in the echocardiographic parameters.

\section{DISCUSSION}

The present case demonstrates the feasibility of guiding a TAVI exclusively with TEE and represents one step further on the role of TEE in TAVI procedures. The usefulness of

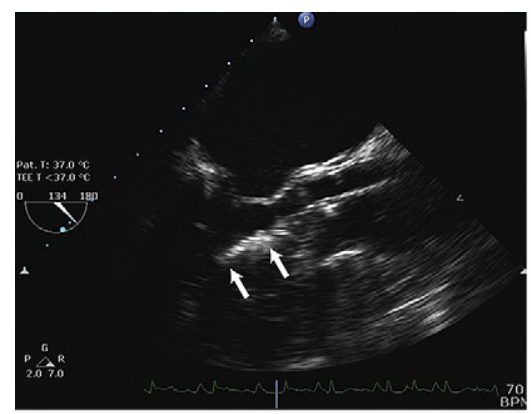

A

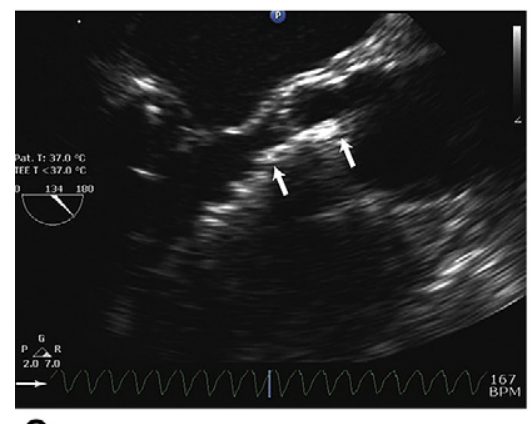

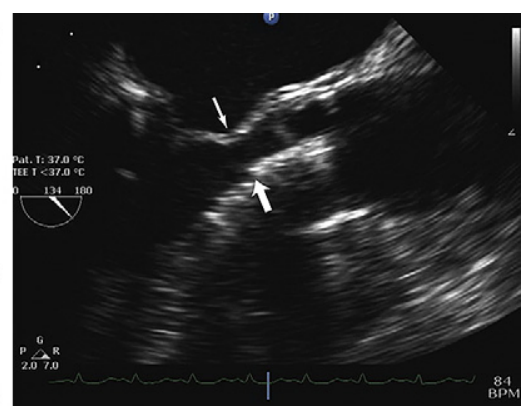

B

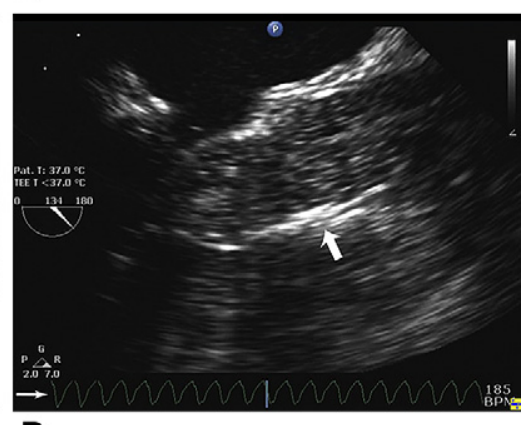

D

FIGURE 1. TEE images (long-axis view) during transapical aortic valve implantation. A, Transcatheter valve in the left ventricular cavity before deployment showing the ventricular and aortic ends of the stent containing the valve (white arrows). B, Accurate positioning of the valve using the hinge point of the anterior mitral leaflet (thin white arrow) as a marker for the ventricular end of the valve (thick white arrow). C, Verification of the position of the valve (thick white arrows) under rapid pacing (thin white arrow) just before deployment. D, Valve deployment by balloon inflation (thick white arrow) under rapid pacing (thin white arrow). 

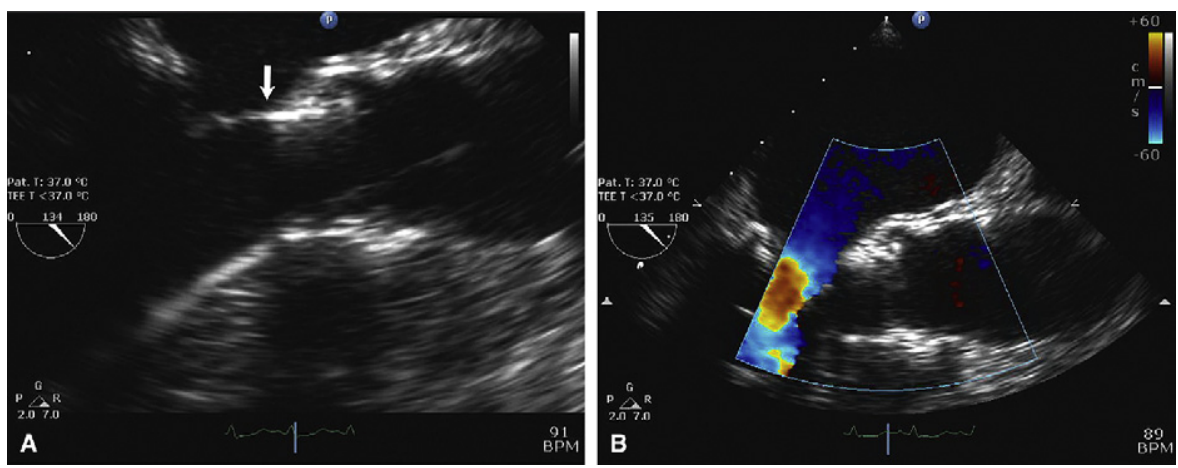

FIGURE 2. TEE images (long-axis view) after valve implantation showing the adequate position of the transcatheter valve, with the ventricular end of the stent containing the valve (white arrow) at the level of the hinge point of the mitral valve (A) and the absence of paravalvular aortic regurgitation (B).

echocardiography in TAVI has been outlined in previous studies, ${ }^{3,4}$ but very little data exist on the role of TEE during a key point of the TAVI procedure such as valve positioning and deployment. In fact, an error during valve positioning can be associated with a life-threatening complication such as valve malposition or embolization. ${ }^{5}$ Up to now, angiography has been the gold standard for valve positioning and deployment. However, obtaining an adequate angiographic view of the aortic valve can be difficult and usually requires several contrast injections with the subsequent increased risk of contrast-induced nephropathy. Also, deciding the final position of the transcatheter valve on the basis of angiographic images might be challenging and, again, usually necessitates several contrast injections. As has been shown in the present report, TEE can provide very accurate images of the transcatheter valve before deployment (Figure 1). Also, TEE allows the use of other anatomic markers such as the mitral valve, which probably makes TEE a more reliable and reproducible technique for valve positioning. However, in some instances the echocardiographic images do not allow a clear differentiation between the stent containing the valve and the balloon on which the stent has been crimped. This may be partially related to the lack of coaxiality of the valve-balloon system, especially in those cases in which the transfemoral approach is used. Also, extremely severe calcification of the aortic valve and annulus may somewhat reduce the quality of echocardiographic visualization of the prosthetic valve, which may limit the performance of TEE for the guidance of valve positioning.

We thank Drs Sebastien Bergeron, Jacques Villeneuve, Robert DeLarochellière, Rodrigo Bagur, Olivier F. Bertrand, and Philippe Pibarot from the Laval Hospital for their help during the procedure and the careful review of the manuscript. We also thank Mark Dedahstian, MS, from Edwards Lifesciences Inc, for his help in the preparation of the manuscript.

\section{References}

1. Webb JG, Lichtenstein S. Transcatheter percutaneous and transapical aortic valve implantation. Semin Thorac Cardiovasc Surg. 2007;19:304-10.

2. Rodés-Cabau J, Dumont E, DelaRochellière R, Doyle D, Lemieux J, Bergeron S, et al. Feasibility and initial results of percutaneous aortic valve implantation including selection of the transfemoral or transapical approach in patients with severe aortic stenosis. Am J Cardiol. 2008;102:1240-6.

3. Moss RR, Ivens E, Pasupati S, Humphries K, Thompson CR, Munt B, et al. Role of echocardiography in percutaneous aortic valve implantation. J Am Coll Cardiol Cardiovasc Imging. 2008;1:15-24.

4. Berry C, Oukerrai L, Asgar A, Lamarche Y, Marcheix B, Denault AY, et al. Role of transesophageal echocardiography in percutaneous aortic valve replacement with the Corevalve Revalving system. Echocardiography. 2008;25:840-8.

5. Tuzcu ME. Transcatheter aortic valve replacement malposition and embolization: innovation brings solutions also new challenges. Catheter Cardiovasc Interv. 2008; 72:579-80. 